Women outperform men in remembering to remember

Liana Palermo ${ }^{1,2^{*}}$, Maria Cristina Cinelli ${ }^{3}$, Laura Piccardi ${ }^{2,4}$, Paola Ciurli $^{2}$, Chiara Incoccia ${ }^{2}$, Laura Zompanti $^{3}$ \& C. Guariglia ${ }^{2,3}$

${ }^{1}$ School of Life and Health Sciences, Aston University, Birmingham, UK

${ }^{2}$ Neuropsychology Unit, IRCCS Fondazione Santa Lucia of Rome, Italy

${ }^{3}$ Department of Psychology, “Sapienza” University of Rome, Italy

${ }^{4}$ Department of Life, Health and Environmental Sciences, L’Aquila University, L’Aquila, Italy

\title{
*Liana Palermo
}

School of Life and Health Sciences,

Aston University, Birmingham, UK

l.palermo@aston.ac.uk 


\begin{abstract}
The study of gender differences in prospective memory (i.e., remembering to remember) has received modest attention in the literature. The few reported studies investigating either subjective or objective evaluations of prospective memory have shown inconsistent data. In this study, we aimed to verify the presence of gender differences during the performance of an objective prospective memory test by considering the weight of specific variables such as length of delay, type of response and type of cue. We submitted a sample of 100 healthy Italian participants (50 men and 50 women) to a test expressly developed to assess prospective memory: The Memory for Intentions Screening Test. Women performed better than men in remembering to do an event-based task (i.e., prompted by an external event) and when the task required a physical response modality. We discuss the behavioural differences that emerged by considering the possible role of sociological, biological, neuroanatomical and methodological variables.
\end{abstract}




\section{Introduction}

There is increasing evidence that women are better than men at remembering details from past episodes (Wang, 2013). According to Herlitz and Rehnman (2008), the general female advantage in episodic memory is more evident in verbal episodic memory tasks, because of women's advantage over men in verbal production, but it may be reversed in tasks requiring visuospatial processing because of men's better visuo-spatial skills. However, the female advantage was confirmed in several studies in which tasks were manipulated to prevent the verbalization of items (Lewin \& Herlitz, 2002). This suggests that there are sex differences in episodic memory regardless of the nature of the material that has to be remembered. At this point one could wonder if this female advantage is specific for retrospective memory or whether it also involves the ability of "remembering to remember". In other words, are there also gender differences in the prospective memory skill?

Prospective memory is defined as remembering to perform an intended action at some time in the future (Brandimonte, Einstein, \& McDaniel, 1996; Meacham \& Leiman, 1982). Besides recalling the content of a task, a crucial aspect of this kind of memory is being able to retrieve it at the right moment (Ellis \& Kvavilashvili, 2000). To the best of our knowledge, the study of gender differences in prospective memory has received modest attention until now. Although current studies have used either subjective (Crawford, Smith, Maylor, Della Sala, \& Logie, 2003; Piauilino et al., 2010) or objective (Ceci \& Bronfenbrenner, 1985; Huppert, Johnson, \& Nickson, 2000; Maylor \& Logie, 2010) prospective memory measures, the weight of specific variables affecting performance (i.e., length of delay, type of response and type of cue; see below for details) has not always taken into account. The few studies that have used objective measures of prospective memories have investigated this function in children (Ceci \& Bronfenbrenner, 1985), older adults (Huppert, Johnson, \& Nickson, 2000) and the only one on a larger range of age sample (from 8 to 50 years of age) used a Web-based experiment (Maylor \& Logie, 2010). 
Furthermore, the effect of gender on prospective memory is still unclear. In fact, some studies found that women reported more prospective memory failures than men (Piauilino et al., 2010), others reported that women outperform men (Huppert et al., 2000; Maylor \& Logie, 2010) and others found no gender differences (Crawford et al., 2003). Note that the ability to subjectively evaluate ourselves is different from actual performance of a specific task. For example, older adults, who usually perform worse than younger people on objective prospective memory tasks (e.g., Maylor, 1996; Zeintl, Kliegel, \& Hofer, 2007), did not evaluate themselves worse than younger people (Crawford et al. 2003; Piauilino et al., 2010). Similarly, gender might also affect performance on an objective prospective memory task differently from how it affects a subjective evaluation.

When formulating a hypothesis about the effect of gender in objective memory tasks, one should take into account that such tasks involve at least two components: the prospective component, that is, becoming aware at the appropriate moment that one had an intention to carry out a certain action, and the retrospective component, that is, retrieval of the intended action from long-term memory (Kvavilashvili, 1987; Einstein \& McDaniel, 1996). Recollection of a specific action to perform (retrospective component) is likely mediated by the episodic memory system, which is also responsible for the memorization of previous experiences (Kvavilashvili, 1987; Carlesimo, Casadio, \& Caltagirone, 2004). Thus, one should expect to find a female advantage in prospective memory tasks due to the better episodic memory reported in women (Bloise \& Johnson, 2007; Herlitz, Airaksinen, \& Nordström, 1999; Herlitz, \& Yonker, 2002). But, considering that successful performance on a prospective memory task also requires other processes, such as monitoring the environment to detect the prospective memory cue and/or checking the passing of time, a male advantage in these other processes (Ceci \& Bronfenbrenner, 1985) might balance the female advantage for retrospective memory, resulting in the absence of gender differences on a prospective memory task.

Also note that performance on prospective memory tasks may vary due to the particular characteristics of the task, such as response modality, type of cue or length of the delay interval 
(Koriat, Ben-Zur, \& Nussbaum, 1990; Uttl, Graf, Miller, \& Tuokko, 2001; Meacham \& Leiman, 1982; Hicks, Marsh, \& Russell, 2000, Raskin, 2009). For example, remembering to call the doctor at 2:30 pm (time-based task) could be more difficult than performing an action prompted by an external event, for example, taking medication after lunch (event-based task). There is agreement that time-based tasks are more difficult than event-based tasks (due to the greater level of internal monitoring required by the former; Henry, MacLeod, Phillips, \& Crawford, 2004; McDaniel \& Einstein, 2007; Raskin, 2009), but data are mixed regarding other variables, such as kind of response. Indeed, some authors reported that prospectively recalling an action was performed better than prospectively recalling verbal information (Goschke \& Kuhl, 1993; Koriat et al., 1990), but others found the opposite pattern (Brooks \& Gardiner, 1994; Schaefer, Kozak, \& Sagness, 1998). Differences among studies could be due to differences in the kind of prospective memory tasks used or in the study design (see Engelkamp, 1997). Moreover, differences in the recruited samples (i.e., the ratio between males and females) might also account for the inconsistency among studies. Indeed, to the best of our knowledge the effect of gender on specific attributes of prospective memory tasks has never been investigated.

In this study, we aimed to verify the presence of gender differences during performance of a prospective memory test by systematically determining whether performances were affected by specific variables such as length of delay, type of response and type of cue. Thus, we tested a sample of 100 healthy Italian participant (from 15 to 40 years of age) using a test specifically developed to assess prospective memory and the Memory for Intentions Screening Test (MIST; Raskin, 2004; Woods, Moran, Dawson, Carey, Grant, 2008). Indeed, at variance with other standardized instruments (e.g. the two prospective memory tasks included in the Rivermead Behavioural Memory Test; Wilson, Cockburn, \& Baddeley, 1990), the MIST takes into account specific variables that can affect performance (i.e., length of delay, type of response and type of cue). In addition, to the best of our knowledge, we investigated, for the first time, this function with an objective task and in a laboratory setting, focusing on a sample ranged from 15-40 years of age. 
This is a span of age characterized by hormonal differences between men and women that can turn in specific gender differences in different cognitive skills (e.g. Driscoll, Hamilton, Yeo, Brooks, Sutherland, 2005). For example studies on spatial cognition suggest that gender differences emerged in adolescence (Linn \& Peterson, 1985) and other studies did not observe differences until 15 years of age (see for instance Farrell Pagulayan, Busch, Medina, Bartok, \& Krikorian, 2006 ).

\section{Methods}

\section{Participants}

Participants included 100 healthy individuals with no history of neurological or psychiatric disorders (age range: 15-40 years). The sample included 50 women (age: mean $=24.68$ years, $\mathrm{SD}=$ 6.85; education : mean $=13.32$ years, $\mathrm{SD}=3.61)$ and 50 men $($ age $:$ mean $=24.92$ years, $\mathrm{SD}=6.81$; education: mean $=12.34$ years, $\mathrm{SD}=3.17)$.

All participants showed normal reasoning ability when assessed with Raven's Coloured Progressive Matrices (Basso, Capitani, \& Laiacona, 1987).

Female and male participants did not differ with respect to age $\left(\mathrm{F}_{(1,98)}<1\right.$; $\mathrm{p}=.86$; partial $\eta^{2}<0.01$; MSe $=46.60)$, education $\left(\mathrm{F}_{(1,98)}=2.08 ; \mathrm{p}=.15\right.$; partial $\eta^{2}=.21$; MSe $\left.=11.53\right)$ or reasoning skills $\left(\mathrm{F}_{(1,98)}=2.87 ; \mathrm{p}=.09 ;\right.$ partial $\left.\eta^{2}=.28 ; \mathrm{MSe}=6.44\right)$.

The study was approved by the local Ethics Committee and all participants gave their written informed consent according to the 1964 Declaration of Helsinki.

\section{Materials and procedure}

The experimental protocol was carried out in a quiet well-lit room. All participants were tested by a female examiner.

After signing the informed consent document, participants were administered the Raven’s Coloured Progressive Matrices (Basso et al., 1987). All participants performed within the normal range on this reasoning test. 
Then they were submitted to the MIST (Raskin, 2004); they had to perform 8 prospective memory tasks while they were engaged in a word-search puzzle to prevent overt rehearsal of the prescribed intentions (see Raskin, 2009 and Woods et al., 2008).

The eight trials take into account the following variables:

length of the delay interval, which is either short (2 minutes) or long (15 minutes);

types of cues, that is, time-based (e.g. "In 2 minutes, ask me what time this session ends”), or eventbased (e.g. "When I show you a postcard, self-address it”) cue;

response modality, that is, a verbal (e.g. "In two minutes, ask me what time this session ends”) or a physical (e.g. "When I show you a postcard, self-address it”) response.

For each trial a score equal to 2 was awarded for a correct response (for the time based trials an answer was scored as correct if provided at the correct time \pm 1 minute) while one point was awarded for a correct answer, but provided at the wrong time or vice-versa for a wrong answer but provided at the right time. For example, if a participant was 10 minutes early in asking for a break one point was awarded for that trial. A score equal to zero was awarded for an incorrect response provided to an associative cue (as in Raskin et al., 2004) or when both the time and the answer were incorrect.

Each trial contributes to three of the MIST's six subscales (2-min delay period; 15 min delay period; event based; time based; verbal response and physical response subscale), as determined by each trial's delay (2 vs 15 minutes), cue (event/time based), and response modality (verbal/ physical). Separate scores were calculated for the 2-min delay period (maximum score 8), 15-min delay period (maximum score 8), time-based (maximum score 8), event-based (maximum score 8), verbal response (maximum score 8) and action response (maximum score 8) trials. These six separate scores were summed to obtain a summary score, ranging from 0 to 48 (MIST summary score).

The MIST also includes a recognition test, which is performed when the eight MIST trials (MISTRecognition) are completed; it includes 9 multiple-choice items, which evaluate whether participants recalled the actual content and rules of all of the eight MIST trials. One point is given 
for each question correctly answered (maximum score 8).

Finally, there is a 24-hour delay trial (MIST-24hour) in which participants have to telephone or text the examiner after 24 hours and report how many hours they slept the night after the testing (score range: $0-2 ; 0=$ incorrect response; $1=$ correct response but in the wrong time; $2=$ correct response in the right time).

\section{Statistical analysis}

To detect gender differences in the experimental tasks, we performed ANOVAs comparing the performances of women and men using the MIST summary score, MIST Recognition task score and MIST 24-hour task score.

To determine whether gender differences were present with respect to types of cues (time-based vs. event-based), response modality (verbal vs. physical), length of the delay interval (i.e., short 2minute or long 15-minute, delay period) 2 x 2 mixed ANOVAs were performed followed by posthoc analysis (Bonferroni Test) when necessary. In addition, to rule out extraneous factors (i.e. reasoning skills, education) we also performed ANCOVAs with score at Raven's Coloured Progressive Matrices and the years of education as covariates.

It was not possible to run a 4 way ANOVA with gender as a between-subject factor, and type of cue, response modality, and length of the delay as within-subject factors for methodological reasons related to the test. Each individual trial contributes to three of the MIST's six subscales (as determined by each trial's specific delay, cue, and response characteristics) and each subscale is determined by four individual trials. So at the end this test allows to have 6 scores (event based, time based, 15 minutes, 2 minutes, physical, verbal), but the length of delay, modality and type of cue are not balanced across trials and this makes impossible to perform such analysis (for example there are 2 trials “event based/ 15 minutes delay/physical” and none “event based/ 15 minutes delay/verbal”). 


\section{Results}

No statistically significant differences emerged between men and women in the MIST summary score $\left(\mathrm{F}_{1,98}<1, \mathrm{p}=.38\right.$; partial $\left.\eta^{2}<.01 ; \mathrm{MSe}=26.82\right)$, MIST Recognition task score $\left(\mathrm{F}_{1,98}<1, \mathrm{p}=\right.$ .48 ; partial $\eta^{2}<.01$; MSe $\left.=.18\right)$ or MIST 24-hour task score $\left(\mathrm{F}_{1,98}<1, \mathrm{p}=1\right.$; partial $\eta^{2}<.01$; $\mathrm{MSe}=$ .71). See Table 1 for means and SDs.

To determine whether gender differences were present with respect to types of cues (time-based vs. event-based), a 2 x 2 mixed ANOVA (Gender x Types of cues) was performed. ANOVA showed a non-significant main effect of gender $\left(\mathrm{F}_{(1,98)}=.76 ; \mathrm{p}=.39\right.$; partial $\eta^{2}<.01$; MSe $\left.=1.49\right)$ and a significant main effect of types of cues $\left(\mathrm{F}_{(1,98)}=18.6 ; \mathrm{p}<.001\right.$, partial $\eta^{2}=.16$; MSe $\left.=.76\right)$. In particular, the time-based trials (mean=6.89; $\mathrm{SD}=1.15$ ) were more difficult than the event-based trials $($ mean $=7.42 ; \mathrm{SD}=.99)$. A significant Gender $\mathrm{x}$ Types of cues interaction was detected $\left(\mathrm{F}_{(1,98)}\right.$ $=7.21 ; \mathrm{p}<.01$, partial $\eta^{2}=.07 ;$ MSe $=.76$ ). Post-hoc analysis (Bonferroni Test) showed that women performed better on the event-based $($ mean $=7.66$; $\mathrm{SD}=0.75)$ than on the time-based (mean $=6.80$; $\mathrm{SD}=1.09)$ trials $(\mathrm{p}<.001)$, whereas men's proficiency $(\mathrm{p}=.25)$ was the same on both the eventbased $($ mean $=7.18 ; \mathrm{SD}=1.14)$ and the time-based trials $($ mean $=6.98 ; \mathrm{SD}=1.2)$. Furthermore, women performed better than men on the event-based trials $(p<.05)$; no gender differences were detected for the time-based trials $(p=.43)$. To further investigated the presence of a truly gender difference in the event based tasks, we performed a 2 × 2 ANCOVA with scores at Raven's Coloured Progressive Matrices and the years of education as covariates. The analysis showed no change in the reported effect because we found a significant Gender x Types of cues interaction effect $\left(\mathrm{F}_{(1,96)}=8.1 ; \mathrm{p}<.01\right.$, partial $\left.\eta^{2}=.08\right)$. Post-hoc analysis (Bonferroni Test) showed that women performed still significantly better than men on the event based trials $(p=.01$; Women Adjusted Mean = 7.67; Men Adjusted Mean = 7.17).

Concerning the length of the delay interval (i.e., short 2-minute or long 15-minute, delay period) a 2 x 2 mixed ANOVA (Gender x Length of delay interval) showed a non-significant main effect of gender $\left(\mathrm{F}_{(1,98)}=.76 ; \mathrm{p}=.39\right.$, partial $\left.\eta^{2}<.01 ; \mathrm{MSe}=1.49\right)$ and a significant main effect of length of 
the delay interval $\left(\mathrm{F}_{(1,98)}=75.67 ; \mathrm{p}<.001\right.$; partial $\eta^{2}=.43$; MSe $\left.=1.35\right)$. In particular, the 15minute delay period trials (mean $=6.44 ; \mathrm{SD}=1.62$ ) were more difficult than the 2 -minute delay period trials $($ mean $=7.87$; $\mathrm{SD}=.44$ ). The interaction Gender $\mathrm{x}$ Length of delay interval was not statistically significant $\left(\mathrm{F}_{(1,98)}=.63 ; \mathrm{p}=.43\right.$; partial $\eta^{2}<.01$; MSe $\left.=1.35\right)$. Finally, to determine whether gender differences were present with respect to the response modality (verbal vs. physical), a 2 x 2 mixed ANOVA (Gender x Response modality) was performed, showing a non-significant main effect of gender $\left(\mathrm{F}_{(1,98)}=.76 ; \mathrm{p}=.39\right.$; partial $\eta^{2}<.01$; MSe $\left.=1.49\right)$. The main effect of types of response modality tended towards significance $\left(\mathrm{F}_{(1,98)}=3.63 ; \mathrm{p}=.06\right.$; partial $\eta^{2}<.03$; MSe $=.73$; physical response trials: mean= $7.04, \mathrm{SD}=1.21$; verbal response trials: mean $=7.27$; $\mathrm{SD}=.90$ ). $\mathrm{A}$ significant Gender x Response modality interaction emerged $\left(\mathrm{F}_{(1,98)}=7.47 ; \mathrm{p}<.01\right.$; partial $\eta^{2}=.07$; MSe $=.73)$. Post-hoc analysis (Bonferroni) showed that men performed better $(\mathrm{p}<.001)$ in verbal response trials $($ mean $=7.36 ; \mathrm{SD}=.9)$ than in physical response trials $($ mean $=6.8 ; \mathrm{SD}=1.38)$ and women performed verbal response $($ mean $=7.18 ; \mathrm{SD}=.9)$ and physical response $($ mean $=7.28$; $\mathrm{SD}$ $=.95)$ trials without significant differences $(p=.56)$. Furthermore, women performed better than men in the physical response trials $(\mathrm{p}<.05)$; no gender differences were detected in verbal response trials.

To further investigated the presence of a truly gender difference in the physical response trials, we performed a 2x2 ANCOVA with the score at Raven’s Coloured Progressive Matrices and the years of education as covariates. The analysis showed no change in the reported effect because we found a significant Gender x Response modality interaction effect $\left(\mathrm{F}_{(1,96)}=8.33\right.$; $\mathrm{p}<.01$, partial $\left.\eta^{2}=.08\right)$. Post-hoc analysis (Bonferroni Test) showed that the women performed still significantly better than men in physical response trials $(\mathrm{p}<.05$; Women Adjusted Mean = 7.29; Men Adjusted Mean = 6.79).

\section{Discussion}


There is evidence that women are better than men in remembering past events (Wang, 2013), but whether this gender difference is also true for prospective memory, that is, for remembering to perform a future task (e.g. stopping to buy milk at the supermarket on the way home from work) is still unclear.

In this study, we analysed the presence of gender differences in prospective memory by also evaluating the weight of specific variables such as length of delay, type of response, and type of cue (event-based vs time-based). At variance with previous studies in which the presence of gender differences was evaluated using subjective measures (i.e. evaluation of meta-memory; Crawford et al., 2003; Piauilino et al., 2010), in older adults (Huppert, Johnson, \& Nickson, 2000) or using Web-based experiment (Maylor \& Logie, 2010), we used a performance test (i.e., the Memory for Intentions Screening Test - MIST; Raskin, 2004), which objectively evaluates prospective memory, testing young adults and adults in a laboratory setting.

As already reported in previous studies (Henry et al., 2004; McDaniel \& Einstein, 2007; Raskin, 2009; Goschke \& Kuhl, 1993; Koriat et al., 1990), specific variables affected performance on prospective memory tasks. Specifically, we found that more prospective errors were made in the time-based than the event-based tasks, when the length of the delay interval was longest (15minutes) and tended to be greater when a verbal response had to be given.

The novelty of our study lies in the results on gender differences. At variance with some previous studies that showed the presence of gender differences with both subjective measures (Piaulino et al., 2010) or objective measures (Huppert et al., 2000; Maylor \& Logie, 2010), the present data showed no differences when the overall test performance (i.e., MIST-summary score), the recognition test (i.e., MIST-Recognition) or the 24-hour delay test (i.e., MIST-24hour) was considered. However when the weight of specific variables was taken into account, we found that women performed better than men in remembering to perform an action in the event-based tasks (i.e., in tasks prompted by an external event, such as "When I show you a postcard, self-address it), and when the task required a physical response modality (e.g. "When I show you a postcard, self- 
address it”). These results, which demonstrate the presence of specific gender differences in eventbased tasks and in prospectively remembering to perform actions, are consistent with that of previous researches with objective tasks that have been carried out using the internet methodology (as in Maylor \& Logie, 2010) or by testing older participants (above 65 years as in Huppert et al., 2000). The present study extends previous research by demonstrating the presence of gender differences in a laboratory setting and in a 15-40 years old sample. Considering the relative small size of our sample, caution is however necessary in drawing conclusion. Future studies on bigger sample or meta-analysis could help in define the size of this gender effect.

A comment deserve the evidence that our results are in contrast with the findings of some previous studies showing more prospective memory failures in women than in men (Piauilino et al., 2010) or the absence of any gender difference (Crawford et al., 2003) in self-evaluation of prospective memory. The different resultscan probably be attributed to the use of a self-evaluation questionnaire in these previous studies and consequently to a possible discrepancy between the self-evaluation of a cognitive skill and the actual level of performance. Indeed, it is not surprising that the subjective evaluation of one's own skills is not always congruent with the objective measure of the same skills. For example, some studies on ageing report that although age affects performance on objective prospective memory tests, it does not affect the subjective memory rating (Crawford et al., 2003). Differences between objective and subjective measures have been attributed to the tendency to rate memory relative to one's peers (Rabbitt, Maylor, McInnes, Bent \& Moore, 1995). Thus, we can speculate that when women rated themselves in prospective memory questionnaires they compared their skills with those of other women, not men. The possibility also has to be considered that women recall their prospective memory failures better than men. Thus, the differences revealed by self-evaluation do not refer to the actual number of failures but to the different ability to recognize and recall them. In any case, this issue can only be clarified in future studies in which objective and subjective measures of prospective memory are directly compared in the same participants. 
The present data suggest various interpretations of the mixed results reported in previous studies on gender differences in prospective memory. Considering that a prospective memory task involves a retrospective component (Kvavilashvili, 1987, Einstein \& McDaniel, 1996) that is mediated by the episodic memory system responsible for the memorization of previous experiences (Kvavilashvili, 1987; Carlesimo et al., 2004), the female advantage in prospective memory might just be a consequence of the better episodic memory often reported in women. Note, however, that in the recognition test (MIST-Recognition) we did not find a female advantage. Moreover, if the female advantage is related to the retrospective component, we should have found an overall female advantage, irrespective of variables such as kind of cue (event-based vs. time-based) or response modality. Instead, we found that women were better in performing a task prompted by an external cue and a task requiring a physical response.

The finding that sex differences emerge when specific variables are considered raises a question about whether the female advantage is truly a prospective memory advantage or is due to sex differences in other cognitive skills. For example, the women’s better performance could have been due to the well-known female advantage in verbal skills, because the instructions of the MIST trials were verbally mediated. If this is the case, once more, why did we find female advantage only when specific variables were taken into account and not when the response modality was verbal but, rather, physical? By contrast, the evidence that women perform better than men in event-based but not time-based tasks might indicate that there really is a female advantage in prospective memory, but that it may “decrease” in tasks requiring a greater level of internal monitoring (i.e., time-based tasks) because of the male advantage in tasks requiring a high working memory load (Coluccia \& Louse, 2004). The female advantage in these tasks also can be explained by evidence that women exhibit field dependence (Waber, 1977) and rely on environmental information more than men.

The presence of gender differences in prospective memory prompts the question regarding a possible biological basis of this difference. Difference in the levels of circulating hormones can represent one possibility. Indeed, in other cognitive domain (spatial knowledge) specific patterns of 
relationships between circulating testosterone and performance have been reported (Choi \& Silverman, 2002; Silverman et al., 1999). However it is interesting to note that in a study with an older sample (above 65), Huppert et al. (2000) found a women advantage in prospective memory despite the fact that this period of life correspond to menopause (i.e., hormonal changes).

The presence of gender differences could be due to the presence of gender differences in specific brain structures such as the hippocampus. Indeed, in early adulthood gender differences have been detected in the hippocampus (Pruessner et al., 2001). Specifically only men showed a decline between the third and fifth life decade in the hippocampus volume. Hence, it can be speculated that men in early adulthood show a decline in memory tasks subserved by hippocampus when compared with women. A positive relationship has been recently reported between the hippocampus volume and accuracy on a focal prospective memorytask, but this association was not reported for non-focal tasks (Gordon et al., 2011). At variance with non-focal tasks, in focal prospective memory tasks some information of the ongoing activity overlap with the encoded prospective memory cue, triggering spontaneous retrieval of the associated response. Similarly, considering that event-based prospective memory is supported by cue-driven spontaneous retrieval processes, which may be subserved by the hippocampus (Gordon et al., 2011), the gender differences for this aspect of prospective memory could be the consequence of hippocampal gender differences in early adulthood (Pruessner et al., 2001).

An alternative hypothesis is that the sex differences we found could have been due to the caretaking role often assumed by women and the fact that in addition to work responsibilities women also have more responsibilities at home (Seeman \& McEwan, 1996; Long et al., 1999). As a consequence of this social role, in daily life women might perform tasks involving prospective memory/planning skills more than men, thus enhancing their performance in remembering to remember. In addition, the different roles of women and men in society might have produced differences in specific neural correlates that, in turn, might be the basis of gender differences in behavioural performance in prospective memory tasks. 
Unfortunately in this study was not possible to investigate the relation between performance and hormonal status and future studies investigating this relation (e.g. studies in which that look at differences in women's performance in different phases of the menstrual cycle or when hormonal contraceptives are used) could help in disentangle between social and biological hypotheses. Research investigating sex differences in prospective memory tasks with neuroimaging techniques could also shed more light on this topic and help clarify different interpretations.

In sum, in this study we found a female advantage in prospective memory using an objective measure. Although we were unable to completely exclude that the differences favouring women in prospective memory are merely a function of sex differences in other skills, we suggest that this advantage is specific for prospective memory. 


\section{References}

Basso, A., Capitani, E., \& M. Laiacona, M. (1987). Raven’s Coloured Progressive Matrices: normative values on 305 adults normal controls. Functional Neurology, 2, 189-194.

Bloise, S.M., \& Johnson, M.K. (2007). Memory for emotional and neutral information: gender and individual differences in emotional sensitivity. Memory, 15, 192-204.

Brandimonte, M.A., Einstein, G.O., \& McDaniel, M.A. (1996). Prospective memory: Theory and applications. Mahwah, NJ: Lawrence Erlbaum Associates.

Brooks, B.M., \& Gardiner, J. M. (1994). Age differences in memory for prospective compared with retrospective subject-performed tasks. Memory \& Cognition, 22, 27-33.

Carlesimo, G.A., Casadio, P., \& Caltagirone, C. (2004). Prospective and retrospective components in the memory for actions to be performed in patients with severe closed-head injury, Journal of the International Neuropsychological Society, 10, 679-688.

Ceci, S. J., \& Bronfenbrenner, U. (1985). “'Don’t forget to take the cupcakes out of the oven’: prospective memory, strategic time-monitoring, and context. Child Development, 56, 152-164.

Choi, J., Silverman, I. (2002). The relationship between testosterone and route-learning strategies in humans. Brain and Cognition, 50, 116- 120.

Coluccia, E., \& Louse, G. (2004). Gender differences in spatial orientation: A review. Journal of Environmental Psychology, 24, 329-340.

Crawford, J., Smith, G., Maylor, E., Della Sala, S., \& Logie, R. (2003). The Prospective e Retrospective Memory Questionnaire (PRMQ): Normative data and latent structure in a large nonclinical sample. Memory, 11, 261-275.

Driscoll, I., Hamilton, D.A., Yeo, R.A., Brooks, W.M. \& Sutherland, R.J. (2005). Virtual navigation in humans: the impact of age, sex, and hormones on place learning. Hormones and Behavior, 47, 326-35 
Einstein, G.O., \& McDaniel, M.A. (1996). Retrieval processes in prospective memory: Theoretical approaches and some new findings, in: M. Brandimonte, G. O. Einstein, \& M. A. McDaniel (Eds.), Prospective memory: Theory and applications (pp. 115-141). Mahwah, NJ: Erlbaum.

Ellis, J., \& Kvavilashvili, L. (2000). Prospective memory in 2000: Past, Present and future directions. Applied Cognitive Psychology, 14, S1-S9.

Engelkamp, J. (1997). Memory for to-be-performed tasks versus memory for performed tasks. Memory \& Cognition, 25, 117-124.

Farrell Pagulayan, K., Busch, R.M., Medina, K.L., Bartok, J.A., Krikorian, R. (2006) Developmental normative data for the Corsi Block-tapping task. Journal of Clinical and Experimental Neuropsychology, 28, 1043-52.

Gordon, B.A., Shelton, J.T., Bugg, J.M., McDaniel, M.A., Head, D. (2011). Structural correlates of prospective memory. Neuropsychologia, 49, 3795-800.

Goschke, T., \& Kuhl, J. (1993). Representation of intentions: Persisting activation in memory. Journal of Experimental Psychology: Learning, Memory, and Cognition, 19, 1211-1226.

Henry, J.D., MacLeod, M.S., Phillips, L.H., \& Crawford, J.R. (2004). A meta-analytic review of prospective memory and aging. Psychology and Aging, 19, 27-39.

Herlitz, A., \& Yonker, J.E. (2002). Sex differences in episodic memory: The Influence of Intelligence. Journal of Clinical and Experimental Neuropsychology, 24, 107-114.

Herlitz, A., Airaksinen, E., \& Nordström, E. (1999). Sex differences in episodic memory: The impact of verbal and visuospatial ability. Neuropsychology, 13, 590-597.

Herlitz, A., \& Rehnman, A. J. (2008). Sex differences in episodic memory. Current directions in Psychological Science, 17, 52-56.

Hicks, J.L., Marsh, R.L., \& Russell, E.J. (2000). The properties of retention intervals and their affect on retaining prospective memories. Journal of Experimental Psychology: Learning, Memory, and Cognition, 26, 1160-1169.

Huppert, F.A., Johnson,T., \& Nickson, J. (2000). High prevalence of prospective memory 
impairment in the elderly and in early-stage dementia: findings from a population-based study. Applied Cognitive Psychology, 14, S63-S81.

Koriat, A., Ben-Zur, H., \& Nussbaum, A. (1990). Encoding information for the future action: Memory for to-be-performed tasks versus memory for to-be-recalled tasks. Memory \& Cognition, 18, 568-578.

Kvavilashvili, L. (1987). Remembering intention as a distinct form of memory. British Journal of Psychology, 78, 507-518.

Lewin, C., \& Herlitz, A. (2002). Sex differences in face recognition: Women's faces make the difference, Brain and Cognition, 50, 121-128.

Linn, M.C., \& Petersen, A.C. (1985). Emergence and characterization of sex differences in spatial ability: A meta-analysis, Child Development 56, 1479-1498.

Maylor, E.A. (1996). Age-related impairment in an event-based prospective-memory task. Psychology and Aging, 11, 74-78.

Maylor, E.A., \& Logie, R.H. (2010). A large-scale comparison of prospective and retrospective memory development from childhood to middle age. The Quarterly Journal of Experimental Psychology, 63, 442-451

McDaniel, M.A., \& Einstein, G.O. (2007). Prospective Memory: An overview and synthesis of an emerging field. Los Angeles: Sage Publications.

Meacham, J.A., \& Leiman, B. (1982). Remembering to perform future actions, in: U. Neisser (Ed.), Memory observed: Remembering in natural contexts (pp. 327-336). San Francisco: Freeman.

Piauilino, D.C., Bueno, O.F., Tufik, S., Bittencourt, L.R., Santos-Silvia, R., Hachul, H., Gorenstein, C., \& Pompéia, S. (2010). The Prospective and Retrospective Memory Questionaire: a populationbased random sampling study. Memory, 18, 413-426.

Pruessner, J.C., Collins, D.L., Pruessner, M., \& Evans, A.C.(2001) Age and gender predict volume decline in the anterior and posterior hippocampus in early adulthood. The Journal of Neuroscience, 21, 194-200. 
Rabbit, P., Maylor, E., Mclnnes, L., Bent, N., \& Moore, B. (1995). What goods can self-assessment questionnaires deliver for cognitive gerontology? Applied Cognitive Psychology, 9, S127-S152.

Raskin, S.A. (2004). Memory for intentions screening test [abstract], Journal of the International Neuropsychological Society, 10, 110.

Raskin, S.A. (2009). Memory for intentions screening test: Psychometric properties and clinical evidence. Brain Impairment, 10, 23-33.

Schaefer, E.G., Kozak, M.V., \& Sagness, K. (1998). The role of enactment in prospective remembering. Memory \& Cognition, 26, 644-650.

Seeman, T.E., \& McEwen, B.S. (1996). The impact of social environment characteristics on neuroendocrine regulation. Psychosomatic Medicine, 58, 459-471.

Silverman, I., Kastuk, D., Choi, J., Phillips, K. (1999). Testosterone levels and spatial ability in men. Psychoneuroendocrinology, 24, 813- 822.

Uttl, B., Graf, P., Miller, J., \& Tuokko, H. (2001). Pro- and Retrospective Memory in Late Adulthood. Consciousness and Cognition, 10, 451-472.

Waber, D.P. (1997). Biological substrates of field dependence: implications of the sex difference, Psychological Bulletin, 84, 1076-1087.

Wang, Q. (2013). Gender and emotion in everyday event memory. Memory, 21, 503-511.

Wilson, B, Cockburn, J., \& Baddeley, A.D. (1990). RBMT- Test di memoria comportamentale di Rivermead. Firenze: Organizzazioni Speciali.

Woods, S.P., Moran, L.M., Dawson, M.S., Carey, C.L., \& Grant, I. (2008). Psychometric Characteristics of the Memory for Intention Screening Test. The Clinical Neuropsychologist, 22, 864-878.

Zeintl, M., Kliegel, M., \& Hofer, S.M. (2007). The role of processing resources in age-related prospective and retrospective memory within old age. Psychology and Aging, 22, 826-834. 
Table 1. Means and SDs of the MIST subscales, MIST-summary score, MIST-Recognition and MIST-24 hour task ( $\mathrm{n}=50$ for each gender).

\begin{tabular}{|c|c|c|c|}
\hline & Gender & Mean & SD \\
\hline Time-based score & $\begin{array}{l}\mathrm{F} \\
\mathrm{M}\end{array}$ & $\begin{array}{l}6.80 \\
6.98\end{array}$ & $\begin{array}{l}1.08 \\
1.20\end{array}$ \\
\hline Evented-based score & $\begin{array}{l}\mathrm{F} \\
\mathrm{M}\end{array}$ & $\begin{array}{l}7.66 \\
7.18\end{array}$ & $\begin{array}{r}.74 \\
1.14\end{array}$ \\
\hline 2-minute delay period & $\begin{array}{l}\mathrm{F} \\
\mathrm{M}\end{array}$ & $\begin{array}{l}7.88 \\
7.86\end{array}$ & $\begin{array}{l}.43 \\
.45\end{array}$ \\
\hline 15-minute delay period & $\begin{array}{l}\mathrm{F} \\
\mathrm{M}\end{array}$ & $\begin{array}{l}6.58 \\
6.30\end{array}$ & $\begin{array}{l}1.33 \\
1.88\end{array}$ \\
\hline Response modality -verbal & $\begin{array}{l}\mathrm{F} \\
\mathrm{M}\end{array}$ & $\begin{array}{c}7.18 \\
7.36\end{array}$ & $\begin{array}{l}.90 \\
.90\end{array}$ \\
\hline Response modality-physical & $\begin{array}{l}\mathrm{F} \\
\mathrm{M}\end{array}$ & $\begin{array}{l}7.28 \\
6.80\end{array}$ & $\begin{array}{r}.95 \\
1.38\end{array}$ \\
\hline MIST-summary score & $\begin{array}{l}\mathrm{F} \\
\mathrm{M}\end{array}$ & $\begin{array}{l}43.38 \\
42.46\end{array}$ & $\begin{array}{l}3.94 \\
6.17\end{array}$ \\
\hline MIST-Recognition & $\begin{array}{l}\mathrm{F} \\
\mathrm{M}\end{array}$ & $\begin{array}{l}7.92 \\
7.86\end{array}$ & $\begin{array}{l}.34 \\
.49\end{array}$ \\
\hline MIST-24 hour & $\begin{array}{l}\mathrm{F} \\
\mathrm{M}\end{array}$ & $\begin{array}{l}1.32 \\
1.32\end{array}$ & $\begin{array}{l}.84 \\
.84\end{array}$ \\
\hline
\end{tabular}


